\title{
SER ATENIENSE: UMA HONRA EM RISCO? O TESTEMUNHO DE ACARNENSES DE ARISTÓFANES
}

\author{
MARIA DE FÁTIMA SOUSA E SILVA* \\ Universidade de Coimbra \\ (Portugal)
}

\section{RESUMO:}

PALAVRAS-CHAVE:

Datada de 425 a. C., Acarnenses - a primeira comédia que conservamos do seu autor, como também da Comédia Antiga -, define-se como uma peça de tema 'político', no sentido moderno: inspirada na administração e na experiência colectiva de uma Atenas, a viver plenamente o seu período democrático. Morto Péricles há escassos quatro anos, a cidade prosseguia um contencioso bélico contra as suas ancestrais concorrentes pela supremacia da Grécia, Esparta acima de qualquer outra cidade à cabeça dessa contestação, perante uma Atenas que se arrogava o título de senhora da Grécia. Em contraposição com o tempo saudoso da vitória sobre a ameaça oriental, de que a memória de Maratona e Salamina preservavam um vivo sentimento, Atenas conhecia, neste final de século, uma experiência de risco, que lhe advinha da mesma hegemonia conquistada sobre as suas aliadas, na guerra contra o invasor persa. É precisamente o período de transição da vitória 
que traz prestígio para a crise que uma guerra, que se anuncia longa, aprofunda aquele que os Acarnenses tomam para seu tema. Os anos de guerra já transcorridos não tinham trazido a Atenas reveses marcantes, embora fossem sofridos os efeitos das incursões com que, anualmente, o inimigo penalizava os seus campos. Somadas. estas duas circunstâncias fomentavam um sentimento patriótico intenso e uma sede profunda de vingança, que arredavam o desejo sério de uma paz duradoura dos projectos da maioria. É este o sentido do quadro político, nas suas linhas gerais, traçado por Acarnenses. ${ }^{1}$

O autor de Acarnenses construía a sua peça a partir de Atenas, pintando, em função do próprio fluir histórico, a imagem que a sua cidade pretendia impor ao mundo seu contemporâneo, dentro e fora da Grécia. Que linhas a definiam, quais os esforços empreendidos nesse objectivo, eis a perspectiva antes de mais valorizada por uma peça que caricatura o sentimento imperialista que cresce numa cidade em hora de consolidar um passo civilizacional decisivo: o que a fez passar de um estádio provinciano e rústico, para se tornar uma comunidade de regime democrático, urbano e cosmopolita. Não se esperará, naturalmente, de uma comédia que descreva, no seu estrito rigor, o processo histórico que rodeia a sua produção. Mas uma peça que caricatura, diante dos Atenienses, os traços principais da sua experiência colectiva tem de ser credível, ou seja, de corresponder, no seu sentido geral, ao que a opinião pública tinha como seu consensual entendimento, ou dificilmente lhe poderia caber o galardão de um primeiro prémio.

É na diplomacia que Atenas aposta para se impor aos que são, no tempo, os pólos internacionais do poder económico e militar entre os seus vizinhos a oriente. Todos os investimentos que visam obter alianças no exterior parecem justificar-se na cidade que quer impor-se também no mundo grego.

É por isso a política externa o tema que domina a ordem do dia na assembleia parodiada por Acarnenses. Os embaixadores responsáveis por missões recentes à Pérsia (cf. Tucídides 2.7.1) e Trácia comparecem, perante o povo ateniense, para prestar contas dos resultados obtidos. Dada a importância das missões diplomáticas, esta é função que exige prestígio e experiência. Atesta-o o título de presbeis (61) que cabe aos embaixadores, que são na peça os que encontramos de regresso da corte persa, ao lado de Teoro, ${ }^{2}$ correlegionário e homem de confiança do influ-

1 Cf. A. W. Gomme. "Aristophanes and politics". In: E. Segal, Oxford Readings in Aristophanes (Oxford 1996) 38.

2 Cf. Vespas 42-51, 418-419, 1236-1242. 
ente Cléon, como emissário à Trácia. Junto do cidadão comum, estas delegações criam uma desconfiança profunda, motivada pelo aparato de que se rodeiam (6263) e pelos custos elevados que representam para o cidadão contribuinte. Pagos a peso de ouro $(65-66,90,137)$, os representantes de Atenas prolongam as missões no estrangeiro $(67,80)$, desenvolvendo um programa itinerante de contactos a que sobra luxo e espavento. A imagem que, à distância, o cidadão comum faz dos seus embaixadores contempla o conforto da viagem, a deslocação em carruagens acolhedoras, luxuosamente apetrechadas, com vista ao bem-estar dos emissários e à mensagem de prosperidade que pretendem dar da cidade da Ática (68-71). Nos locais onde desenvolvem a sua tarefa, multiplicam-se banquetes e recepções (85$86,141)$, em que os anfitriões se não mostram avaros, na percepção do interesse de protocolos de cooperação e aliança.

Mas, ainda que cobertas de aparato e vultuosas nos custos, as missões diplomáticas apresentam-se vazias de resultados, mau grado as promessas de que os embaixadores não são modestos. 'O ourinho persa' $(102-103,114)$ não passa de uma miragem, apesar da presença na Pnix de um representante do Grande Rei, esse espectacular Pseudartabas, 'Aldrabão' de seu nome ele também. Mas virtual é igualmente o reforço militar com que a Trácia colabora através do exército dos Odomantos. Para exercerem o seu papel de mercenários ao serviço de Atenas, os Trácios esperam soldos chorudos, que são um verdadeiro assalto ao bolso do pobre cidadão (159-160). Ao Zé povinho, descontente e sofrido, cabe pagar a factura de uma política dispendiosa, de que se aguardam ainda frutos convincentes. $\mathrm{O}$ que leva o herói da comédia, por definição o cidadão modelo, a negociar uma trégua privada com o inimigo é certamente um sentimento, esse sim partilhado com muitos outros dos seus conterrâneos: o repúdio por uma classe de jovens oportunistas, na mira de missões oficiais pagas pelo Estado, enquanto o cidadão honesto e esforçado, já de uma certa idade como o próprio Diceópolis, serve nas fileiras do combate sem obter quaisquer privilégios ou compensações apreciáveis.

Para além de uma actividade aguerrida de contactos no exterior, Atenas desdobra-se também numa estratégia de recepções, honras e distinções aos seus visitantes ou delegações oficiais. Para o Pritaneu é convidado o representante do Grande Rei (124-125), aí recebido, dentro do protocolo habitual, a expensas do Estado, numa manifestação pública daquela xenia de que, por tradição, Atenas se orgulhava (127). Distinção especial podia constituir a concessão do direito de cidadania, com que a cidade procurava homenagear os seus principais aliados (145147). Com a sua integração nas Apatúrias, o destinatário da distinção convertiase em membro, honoris causa, de uma fratria, com registo reconhecido de cidadão. 
Esta foi uma distinção concedida ao filho de Sitalques, o monarca da Trácia, como uma manifestação de simpatia que esperava retribuição sob forma de apoio militar.

Apesar das críticas da comédia, a verdade é que Atenas se impusera no oriente como uma das principais cidades gregas, ao lado de Esparta, com a qual, também na opinião internacional, disputava a primazia. A par de Heródoto, também Aristófanes reproduz a opinião do Grande Rei a propósito dos Atenienses (647-649). Nesta opinião vai contida a imagem que o mundo de então possuía de Atenas: a de uma cidade marítima, forte pelo prestígio da sua armada, e de um centro cultural, em que o teatro desempenha uma indiscutível função cívica e didáctica. Atenas progredia, portanto, para objectivos mais elevados e promissores, que a projectavam para além do seu passado rústico. A armada, que entrara no projecto de uma Atenas moderna e poderosa pela mão de Temístocles, dera em Salamina, no combate naval contra o invasor persa, provas inequívocas da sua capacidade e impusera-se, em definitivo, como elemento de prestígio para a cidade de Palas. Mas da projecção dos seus festivais de teatro, sobretudo os que revestiam, pela grandeza da organização e pela variedade e número de estrangeiros presentes - caso das Grandes Dionísias -, uma verdadeira projecção internacional. Do contributo das representações teatrais para o prestígio de Atenas no exterior falam os Acarnenses com particular acuidade. Antes de mais, o próprio Aristófanes que ousara, no ano anterior a 425 a. C., em Babilónios, atacar Cléon como representante de uma política opressiva e imperialista contra as cidades gregas suas aliadas, foi vítima de perseguição por parte do visado; e é interessante registar como transcreve o poeta a acusação de que foi vítima (502-503): 'de dizer mal da Cidade na presença de estrangeiros'. Por isso, em Acarnenses, apresentados no festival interno e mais familiar das Leneias - no que chamaríamos a época baixa da oferta turística ateniense -, quando não há, presentes na cidade, estrangeiros nem representantes das outras cidades gregas a pagarem tributos (505-506), o poeta pode expor, sem riscos, as debilidades de uma Atenas que zela pela imagem de uma forma atenta e deliberada.

Que objectivos prioritários visava esta política de engrandecimento no exterior? Convencer, antes de mais, as outras cidades da Grécia, da legitimidade de Atenas a aspirar a uma supremacia, que lhe daria foros de cabeça de um império. Mas, no mesmo projecto, incluía-se o apelo a aliados do exterior - desde logo a Pérsia, tida há poucas décadas como um inimigo ameaçador -, que, com a disponibilização de meios, auxiliassem Atenas no seu objectivo hegemónico. $\mathrm{Na}$ guerra que a definição de um novo xadrez na geografia política grega provocou, o 
mundo helénico conheceu sucessivos ajustes, que vieram alterar a tradição de cada uma das cidades e certamente também as regras do seu relacionamento.

A Lacedemónia constituía o inimigo central, aquele que atraía, entre os Atenienses, um ódio mais ou menos consensual (509-512), sobretudo vigoroso entre os campesinos, as vítimas mais directas das incursões dos inimigos sobre os campos que rodeavam a cidade. Apesar de o equilíbrio de forças não ter permitido um pendor claro no sucesso obtido na guerra, as devastações sobre os campos penalizavam já, de uma forma sensível, as populações rurais da Ática. ${ }^{3}$ Neutral, Diceópolis abre o seu mercado, abrigado por uma trégua meramente utópica, a todas as cidades que nele quiserem negociar, numa generosidade que a Atenas real não permitia.

É esta abertura ficcional ao mundo grego que nos permite medir a posição que Atenas ocupava, desta vez entre as cidades helénicas, de acordo com a situação vigente em 425. Pelas cidades da vizinhança, desde logo Mégara como também Tebas, a capital da Ática era olhada como um grande empório, onde o comércio e os negócios fervilhavam. Poder negociar no mercado de Atenas ou usar os seus portos para exportação de produtos era, para as economias vizinhas, condição de sobrevivência. A noção da importância do seu mercado, como coração económico da cidade, deu à ágora um estatuto político evidente, como o local onde sensibilidades e conflitos meramente diplomáticos se repercutiam. A mais ligeira agitação sentida na convivência do mundo grego põe em estado de sítio o porto e ágora de Atenas, porque cordas vitais da existência da cidade. Imaginemos, como simples exercício, a mais inócua das ofensas: que um Lacedemónio pusesse à venda um cachorrito dos Serífios, uma das mais insignificantes cidades da Grécia, que tivesse encontrado. Em nome do mais modesto dos seus aliados, por uma ofensa igualmente modesta, Atenas reagiria com pruridos de grande dama ofendida e pressurosa na defesa dos seus pergaminhos (544-554). A mobilização para a vindicta poria no mar, numa reacção desmedida, trezentos navios, numa exibição exagerada do seu poder naval. Em simultâneo, a ágora agita-se como barómetro da perturbação causada. Num caos verdadeiramente modelar, a comédia traduz o retrato dessa agitação política e financeira, a testemunhar a suscepti-

3 Tucídides (3. 26) abona como a razia provocada pela invasão da Lacedemónia em 427, dois escassos anos antes da representação de Acarnenses, havia sido particularmente devastadora. 
bilidade que abala o projecto ateniense: 'Pagavam-se os salários, douravam-se as estátuas de Palas, o mercado animava-se com a algazarra geral, media-se o grão. E eram odres, correias para os remos, gente a comprar pipos, alhos, azeite, réstias de cebolas, coroas, sardinhas, flautistas, narizes esmurrados'. Esta Atenas que fervilha na expectativa de um conflito que a imponha como senhora da Grécia vive na abundância. Nada lhe falta, desde os produtos essenciais até bens de consumo a retratar fartura e supérfluo. Mesmo na hora da crise, o dinheiro continua a correr, os salários são garantidos para satisfação de um povo, que olha ainda a restauração das efígies da sua deusa sobre os cascos dos navios como condição de um retrato de prosperidade.

Neste contexto, onde pulsa o vigor político e financeiro da cidade, dominam os sicofantas, como a autoridade pública mais relevante. Conhecidos em toda a Grécia como um produto exclusivo de Atenas, eles são a marca de uma cidade que vive do poder dos negócios e do dinheiro (829, 832, 904 sqq.). Atentos às transações, ei-los prontos ao controle e à denúncia, como fiscais que dominam, num sub-mundo de corrupção, a vida da cidade. Detestados e suspeitos face a qualquer código de rigor e de honestidade, eles são a face oculta de um universo de agitação económica.

O teste a que esta comédia política sujeita a Atenas comercial do momento toma por exemplo o caso próximo da ruptura comercial com Mégara. Vizinha da capital da Ática, Mégara mantinha todas as marcas de um meio rústico e economicamente dependente, mesmo que fossem conhecidos os produtos que constituíam o seu meio de subsistência: as lãs, os bens animais e vegetais (lebres e porcos, pepinos e dentes de alho), para além do sal (519-522). O caso de três prostitutas (523-529), Simeta, a cortesã de Mégara, vítima da inconsequência juvenil de um punhado de folgazões atenienses, que os ofendidos retribuíram com o rapto de duas cortesãs de Aspásia, mais não parece do que uma caricatura de Heródoto (1. 1-4), ${ }^{4}$ porta-voz da tradição de que as guerras que, na história, ficaram como paradigmáticas tiveram origem em raptos de mulheres. Mas, sob este pretexto, impunha-se como decisivo, entre outras causas, o embargo económico que Atenas entendeu fazer a Mégara (cf. Tucídides 1. 67. 4), que esteve na origem do desencadear de hostilidades em todo o mundo helénico: Atenas na condição de adversária,

4 C. H. Foley, "Tragedy and politics in Aristophanes' Acharmians". In: E. Segal, Oxford Readings in Aristophanes (Oxford 1996) 129. 
Esparta na de defensora, colocaram os interesses de Mégara no centro de um conflito de proporções inimagináveis.

Bastou a decisão de Atenas para reduzir à fome a vizinha Mégara e incendiar, numa guerra que iria durar três ruinosas décadas, toda a Hélade. Foi por argumentos económicos, a par dos militares, que Atenas quis impor o seu ascendente. No mercado de Diceópolis, protegido por uma trégua utópica, podem reunir-se os que, na vida real, são inimigos, sem que a fantasia destrua, no essencial, o retrato da realidade. Por isso, mais do que aduzir o decreto de Mégara, ditado por Péricles, como causa de um conflito político-militar, a comédia trouxe a cena os próprios resultados da medida na pessoa de um Megarense que se apresenta no mercado de Diceópolis. Como reprodução da Mégara actual, esta cena é o retrato da fome que o embargo económico, aliado à guerra, produziu. Mas é também, por contraste, um contributo para a definição de uma imagem de Atenas que, poucos anos ainda volvidos sobre o início da guerra, mantém uma vantagem que a poupa à crise em que os seus vizinhos megarenses se encontram mergulhados. $\mathrm{O}$ mesmo é dizer que são compreensíveis as aspirações a um sucesso que as circunstâncias do momento ainda não desiludiam.

Desde as primeiras palavras que pronuncia (729 sqq.), no dialecto da sua terra, ${ }^{5}$ que o recém-chegado ergue uma barreira entre o mundo provinciano de onde provém e o citadino que procura. A Atenas que o Megarense aborda deixou de ser o mercado por onde pode escoar os seus produtos. Afinal em Mégara grassa a fome, e até aqueles que são os seus produtos naturais - o sal e os alhos, 758-763 - se viram arrasados pela ocupação ${ }^{6}$ e decisão política de Atenas. O que a capital da Ática agora representa para a penúria do Megarense é um terreno de oportunidades, onde cada um, à sua medida, possa encontrar uma solução de sobrevivência (cf. Aves 37-38). À falta dos produtos tradicionais que poderia comercializar, o Megarense vem disposto a vender as filhas como se fossem porquinhas, num conhecido equívoco que o grego choiros permite. No seu conjunto, a presença do

5 Cf. G. Verbaarschot, "Dialect passages and text constitution in Aristophanes' Acharnians", Mnemosyne 41 (1988) 269-275; B. M. P. Stracca, "Il Megarese e il Beotico nella testimonianza di Aristofane: problemi di vocalismo", Helikon 31-32 (1992) 395-406.

6 Com a ocupação da ilha de Minoa, desde 427 (cf. Tucídides 3. 51), Atenas bloqueava a região das salinas, na costa sudeste de Mégara. Por outro lado, desde o início da guerra que Atenas arrasava os campos de Mégara e lhe devastava as culturas (Tucídides 2. 31. 3, 4. 66. 1). 
provinciano traz de Mégara uma imagem que obedece, nas suas linhas de força, àquilo que o Grande Rei estabelecera, sobre o caso ateniense, como um padrão de prestígio internacional. Mas a imagem, obedecendo aos mesmos critérios, produz um contraste flagrante com Atenas, dando prova, em consequência, do ascendente da cidade de Palas. Uma marítima, outra rústica, eis o modelo por que Atenas e Mégara se fixaram na opinião colectiva. Mas enquanto a primeira mantém inabalável o seu poderio, sugerido por aquela reacção imaginária a qualquer ofensa que a levaria à mobilização imponderada de trezentos navios, Mégara perdeu por completo a capacidade de produzir e comercializar os bens que a caracterizavam. Tornou-se, por isso, um paradigma de fome e de falência (750-756), de que parece incapaz de se recuperar. Apertada pela pobreza, Mégara cede a Atenas, disposta a vender a própria pele em troca - ironia extrema! - 'de um dente de alho e de uma medida de sal!' (813-814, 830-831), aqueles produtos em que outrora assentava a sua economia. Para além de um negócio que cheira a uma exploração sobranceira - a vida e a gente de Mégara em troca de alguns dos seus produtos -, Diceópolis pode até, perdulariamente, saciar de figos as porquinhas que adquire (801-810). Para além da simbologia sexual que os figos acrescentam à obscenidade da cena, eles são o sinal do contraste entre a fome megarense e a abundância que Atenas preserva dos seus produtos: pode dar e vender os seus figos, saciar os aliados que colocou debaixo do seu domínio, ou seja, numa palavra, controlar economicamente as cidades vizinhas.

Um outro símbolo de Atenas é lançado em cena através da figura de um primeiro sicofanta; porque, como muito bem comenta o Megarense (829): 'Isto é que é uma desgracha! Aqui em Atenas é só gente desta laia!' Ou seja, frente a frente Megarense e sicofanta representam o contraste das cidades a que pertencem: um saloio, provinciano, reduzido à opressão mais completa, a braços com a própria aniquilação, perante o fiscal, corrupto e ousado, que explora um terreno de actividade e de abundância. Às piadas ou soluções grotescas à moda de Mégara (738), responde a arte 'de chicofantar', exclusiva de Atenas (822-823).

Ao Megarense sucede-se, no mercado de Diceópolis, o Tebano. A simples entrada da nova personagem, também ela atraída pelo ascendente comercial de Atenas, marca uma oposição com a que a precede. À fome sucede-se a abundância. Uma Tebas farta revive no modelo que Aristófanes traz a cena; com o Tebano, dobrado sob o peso das mercadorias, vem um escravo e um grupo de flautistas. A música e o poejo marcam o tom da presença tebana. Mas há mais: dos sacos do recém-chegado vai saindo a fartura que constitui a riqueza do solo fértil da Beócia. Para além da boroa que serve de epíteto ao cidadão que a representa - 'um 
beociozinho papa-boroa', 872 -, Tebas desabrocha em toda a sua riqueza de região agrícola: 'orégão, poêjo, estêras, mêchas, patos, gralhas, perdizes, galinholas, carriças, mergulhões' (874-876), mas 'taméim gansos, lebres, raposas, topêras, oriços, gatos, arminhos, fuinhas, lontras' (878-880); abundância em catadupa que termina com o petisco, entre todos apreciado, das enguias do Copaís. Tebas pode, portanto, ombrear com Atenas em fartura e poder comercial. Desta vez o confronto assenta numa base diferente; não se trata de um negócio em que uma parte entra com a esperteza, à falta de meios de sobrevivência, e a outra com a exploração e falsidade, como na cena do Megarense. O equilíbrio entre Tebas e Atenas exprime-se sob a forma de um negócio de troca directa, onde cada um investe o seu produto de excelência. Com que poderá Atenas corresponder ao famoso petisco beócio, as suas enguias sem rival? 'Anchovas do Falero ou loiça' (901-902) poderão ser, da parte ateniense, um souvenir convincente. Não fica seduzido o Tebano com a oferta, de alguma coisa que não poderá fazer sucesso na Beócia como rara. Anchovas e loiça também lá existem. Raridade ateniense, essa, só mesmo aquela 'coisa que lá na temos e que na falta aqui', ou seja, um sicofanta. Como produto de excelência, que merece uma embalagem segura para a viagem, é empacotado Nicarco, um fiscal de corrupção conhecida, um verdadeiro exclusivo ateniense (926-931).

É esta a imagem que Atenas passa para o exterior: a de uma cidade em progresso, que conhece a abundância, e que se dedica sobretudo à produção e comércio dos mais variados produtos. Este ascendente torna-a belicosa e alimenta uma ambição, que parece legitimada pelo desenvolvimento que conhece, de dominar as outras cidades gregas e de se colocar à cabeça de um império. Resta, no entanto, perguntar como se vêem, na experiência do quotidiano que a cidade agora oferece, os seus cidadãos. Que balanço fazem os Atenienses de si próprios? O que significa, para eles, ser Ateniense?

Como em todas as épocas que conhecem uma mudança sensível e rápida, tornou-se natural, entre os Atenienses que se transferiam do poder estável de uma democracia sob a autoridade de um estadista carismático como Péricles, para um modelo de gestão dominado por demagogos, um sentimento saudosista. Olhar e louvar o passado como um paraíso ideal passou a fazer parte da própria reflexão sobre o presente. Por outro lado Acarnenses, como é de resto também tendência geral na comédia de Aristófanes, colocam em confronto um padrão de vida rural, conservador, tradicionalista, com o seu oposto, o modelo citadino, ousado e profundamente politizado. Os Atenienses de velha cepa revivem, neste caso, na população suburbana de Acarnas, a mais atingida pela guerra (182-183, 232), e por- 
tanto a mais saudosa da paz, mas também aquela que conserva a fêvera e os princípios de uma tradição que deixou de ser o que era. Resistência física adquirida na dureza da labuta no campo, força moral própria de quem experimentou dificuldades, provas dadas nas horas decisivas para o futuro e liberdade da pátria, eis o que ressalta da descrição que prepara a entrada em cena de um coro de rústicos, carvoeiros e lavradores de Acarnas (179-181): 'uns tipos já de idade, velhos de boas fêveras, rijos como pedra, de antes quebrar que torcer, combatentes de Maratona, gente de ferro'. A acrescentar à personalidade desta gente dura, que representa o passado rural de Atenas, o capote (184) e o cesto do carvão (331-340) funcionam de emblemas identificativos dos Acarnenses. Sobre eles, como sobre toda a cidade ou mesmo sobre a Grécia inteira, a guerra veio desencadear uma mudança radical de vida, que, no entanto, lhes não alterou as aspirações. Para esta franja da população, que representa o lado mais conservador da vida ateniense, o ideal de vida é o regresso ao passado e a uma normalidade campesina, que assenta na rotina de um quotidiano bucólico. Como sinal de um regresso utópico a um passado de paz, Diceópolis propõe-se a celebração das Dionísias Rurais (201-202), um festival de pujança e de fertilidade. Da prece que dirige a Fales, 'companheiro de Baco', ressalta o ideal de vida recuperado apenas por milagre da fantasia. Dele faz parte o prazer de um copo e de um bom prato comido sem parcimónia, a ausência de uma noção estrita de propriedade, que permite colher, sem sanções, a lenha do vizinho (263-279). Mas mais simbólico é, sem dúvida, o quadro de união com a natureza que Diceópolis retrata na violação impune de 'uma linda lenhadora'.

A esta população habituada à dureza de uma vida rústica sobra agressividade, que a faz sonhar com uma vingança directa, fogosa, mas impensada, sobre o inimigo que lhe destrói campos e culturas (230-232). A natureza desta mentalidade vigorosa, mas azeda e romba, a que falta o polimento urbano de que Atenas se pode considerar um padrão, torna-se óbvia no recontro entre um coro de Acarnenses e um Diceópolis tornado mestre em convencer e em despertar piedade, depois de um banho de Eurípides (352-354): 'É terrível o feitio destes homens, azedo de natureza. Só pensam em agredir, em gritar, e nunca estão dispostos a discutir frente a frente'. Incapaz de argumentar, alheia ao poder que a arte da retórica representa para aqueles que a dominam, esta população rústica constitui uma força política ingénua e maleável. É sensível ao elogio e à falácia, cede ao encanto da demagogia, incapaz de seguir a subtileza de um raciocínio sofístico, mas sempre presa fácil do louvor exagerado e gratuito (370-376). Torna-se, por isso, uma força de voto imprevisível, sobre a qual a demagogia pode exercer uma 
pressão fácil. Agressivos e obstinados, mas profundamente ingénuos perante as novidades citadinas, eis o retrato dos Atenienses de velha cepa.

Porque, na nova Atenas, muitas mudanças se operaram e são bem outras as linhas que definem um cidadão à la mode. Uma decisão tão grave como a que desencadeou a guerra do Peloponeso parece ter na origem esse novo modelo de cidadão, o que actua no mundo do comércio e dos negócios. Aí prosperam 'uns tipinhos miseráveis, de mau quilate, uns infames, que não valem nem um tostão furado, meios estrangeirados' (517-518). Falta de escrúpulos e de carácter, ambição desenfreada, eis o que caracteriza uma sociedade cosmopolita, que aceitou no seu seio a presença e intervenção de imigrantes, que vieram alterar por completo o xadrez social da tradição. Além de permeada de estrangeiros, de origem e de cultura mais ou menos estranhas, Atenas importou também costumes e modas do oriente, que transformaram em 'eunucos', efeminados e dados ao luxo, alguns dos seus cidadãos $(117,121)$. Desde logo os embaixadores são exemplo dessa estranha importação (64). Com aquisições deste tipo, Atenas condenou a pureza e o vigor do seu passado.

Lado a lado com a prosperidade corrupta desta população nova-vaga, a cidade viu-se infriltada também de gente do campo, em fuga das incursões inimigas, a viver, na sua maioria, em condições precárias e sub-humanas (71-72). O mesmo é dizer que a guerra parecia servir os interesses de uma população urbana, em detrimento de uma aristocracia rural e dos próprios lavradores. Eis o retrato da cidade real, que contrasta pelo bulício, superlotação e anarquia social com a imagem de grandeza que deseja oferecer ao exterior. Ou seja, para além do confronto, cada dia mais radicalizado, com o adversário externo, a política de guerra criava também fracturas sociais internas. ${ }^{?}$

Sensível à orientação colectiva que a democracia veio trazer à vida urbana, toda a sociedade no interior das muralhas se concentra num regime politizado, onde a individualidade cede lugar aos comportamentos exigidos pelo nomos público. Viver em Atenas é ser um polites na verdadeira acepção da palavra, ou seja, dar prioridade à intervenção no colectivo em detrimento da physis, os impulsos naturais. É assim sobre o funcionamento do órgão democrático por excelência - a assembleia do povo - que o poeta inicia o retrato citadino de Atenas. Em dia de assembleia, convocada para hora matutina, a Pnix mantém-se vazia, cidadãos e

7 Cf. J. Henderson, "The Demos and the comic competition". In: E. Segal, Oxford Readings in Aristophanes (Oxford 1996) 76. 
magistrados ausentes, retardados nas conversas inúteis do centro da cidade (1926). Ausência, desinteresse, indisciplina, irresponsabilidade geral, falta de dignidade no exercício da função, eis os primeiros sinais de decadência a minarem já uma democracia ainda em vias de afirmação. A corda encharcada em tinta vermelha, como meio de apressar a constituição de um necessário quorum, é a primeira marca repressiva na tendencial inoperância dos órgãos democráticos.

Finalmente constituída, a assembleia é a moldura onde se define a personalidade colectiva dos Atenienses. Acessíveis ao elogio fácil, rústicos e citadinos encontram nessa sensibilidade a sua plataforma de encontro. 'Prontos a tomarem decisões' (630), como também 'prontos a mudarem de decisões' (632), os Atenienses caracterizam-se como uma massa maleável, acessível ao poder do discurso, imprevisível nas suas votações. Incapazes de descortinar a falsidade de desgastados e convencionais elogios - 'cidade coroada de violetas', ou 'cidade de brilho ofuscante', 634-640 -, os Atenienses tornaram-se, na opinião popular, de rijos e resistentes, em amorfos e papalvos. Particularmente vulneráveis seriam sem dúvida os campesinos, dantes impossibilitados de participar na vida política da cidade pela própria distância e afazeres da sua actividade. Agora, porém, que a guerra os afastara dos campos e os tornara parte dos residentes na cidade, possivelmente a sua participação na assembleia era mais activa, não sem que a falta de experiência política fosse, da sua parte, mais evidente. Tanto mais saliente a ousadia de uma voz capaz de lhes dizer a verdade, tal como o jovem poeta se propõe fazer nesse outro recinto público que é o teatro de Dioniso. Contrariando a tendência da oratória política no seu pior estilo, o que o poeta tem de fazer em nome do interesse público é 'ensinar muitas coisas boas, a felicidade por exemplo, sem lisonjas, sem promessas de dinheiro, sem sombra de ludíbrio, sem trafulhices nem catadupas de elogios' (656-657), correndo, se necessário, o risco de ser acusado de 'ridicularizar ou de insultar' a cidade (631). O discurso político subjaz a esta Atenas citadina e democrática, como uma ferramenta que transtornou, de fundo, as bases da própria gestão sociaL

É essa mesma retórica a que anima também os tribunais, onde os processos, tão do gosto dos Atenienses, vibram como fonte de sucesso para os que dominam as subtilezas da palavra. Também neste terreno, duas gerações se digladiam: a dos velhos combatentes das batalhas navais, que mereceriam honras de heróis da pátria, que se vêem humilhados e condenados pelos oradores do momento (676684). Do outro lado estão os jovens acusadores, que representam um modelo de cidadão de sucesso: de ascendência desconhecida - quem sabe se estrangeira, 703. 705 -, promovidos mais por meios ilícitos do que por um verdadeiro mérito, estes profissionais da justiça dominam, sem sombra de dúvida, um discurso fluente e 
agressivo. É difícil, sobretudo à velha geração, aguentar-lhes os golpes, os questionários cerrados, ou os ataques subtis. Parece, portanto, que uma nova geração, que privilegia os dons do espírito sobre a força física e a determinação patriótica, se promove à custa da própria inoperância e desajuste daqueles que representam um modelo de vida passada. Este é o preço de uma evolução rápida, que torna difícil o convívio equilibrado dos diversos sectores sociais (cf. 692-700), num mundo onde coragem, família e amor à pátria se viram ultrapassados pelo êxito fácil, pelo dinheiro e pela popularidade.

A mesma decadência se pode verificar numa outra carreira, evidentemente promissora numa cidade em guerra: a vida militar. Mas também nesse campo o conflito de classes se fazia sentir. Para os privilegiados da sorte, o combate promete lucros e promoções. Daí que a hierarquia militar patrocine, ao lado dos spoudarchidae 'os que correm atrás de um tacho' e dos mistharchidae, 'os que farejam um vencimento’ (595-597) - esses são os generais, jovens citadinos, do tipo dos Lâmacos , os pobres soldados honestos, que participam no combate apenas pelo sentido do dever, como o rústico Diceópolis. Bem remunerados, os oportunistas gozam o privilégio de missões especiais à distância, em terrenos onde não chega a dureza do verdadeiro combate (600-606).

Eis a imagem de uma cidade que vivia ao compasso de uma guerra, que se anunciava longa e penosa, mas que, como todos os tempos de crise, vinha operando o milagre da conversão de uma Atenas rústica e tradicionalista, numa urbe próspera e cosmopolita. Processo esse que, na nitidez dos traços cómicos, se traduzia, a preto e branco, no quadro bem conhecido de uma sociedade democrática, com as suas habituais pechas, onde os oportunistas prosperam e se impõem, e os cidadãos honestos encarnam as pobres vítimas da sua própria honestidade e da permissividade do regime. A verdadeira vitória de Diceópolis está em fazer prevalecer 'uma cidade justa', aquela em que a physis cobre os seus direitos sobre nomos, em que o indivíduo conte e possa satisfazer os seus instintos e necessidades básicos, numa felicidade que é essencialmente apragmon.

\section{RÉSUMÉ:}

\section{MOTS-CLEFS:}

